\title{
Pedagogias queer em ação: personagens de desenhos, questões de gênero e noções de diferença
}

\section{Pedagogies queer in action: cartoon characters, gender issues and concepts of difference}

\author{
Adalberto Ferdnando Inocêncio ${ }^{1}$, Moisés Alves Oliveira ${ }^{2}$
}

\begin{abstract}
Resumo
Nesse artigo, analisamos a constituição de significados de gênero em imagens de algumas personagens de desenhos animados da franquia Cartoon Network Studios. Inspirados pelas perspectias pós-estruturalistas foucaultianas, em sentido amplo e, em sentido estrito, pelas lentes teóricas dos estudos queer, propomos a possibilidade da subversão dos significados dados como postos por uma ordem sexual normativa. Optamos pela metodologia de análise do discurso em articulação com as perspectivas queer como forma de lançar olhares para além das lógicas da normalização, neste caso, priorizando-se as questões de gênero. O objetivo foi esboçar possíveis efeitos de sentido que desenhos animados podem transmitir a seus telespectadores. A análise mostrou que a performatividade de gênero expressa pelas personagens tensionam a ordem sexual normativa, a qual sanciona funções e expressões designadas para cada gênero. Posicionando-se nas fronteiras do que fora atribuído histórica e culturalmente como masculino e feminino, apostamos no fato de que a presença de tais personagens, contracenando em tais superproduções, flexionam noções de diferença no momento mesmo em que, para além de supostamente transitar de um gênero a outro, situam-se mais em territórios hibridos.
\end{abstract}

Palavras-chaves: Estudos queer. Gênero. Personagens.

\begin{abstract}
In this article we analyze the constitution of gender meanings in images of some cartoon characters of the franchise Cartoon Network Studios. Inspired by Foucault's poststructuralist perspectives, in a broad sense and in the strict sense, the theoretical lens of queer studies, we propose the possibility of subverting the meanings given as laid by a normative sexual order. We opted for a joint discourse analysis in methodology with queer as a way to launch looks beyond the logics of domination, in this case, giving priority to gender issues. The objective was to outline the possible effects of meaning that cartoons can pass on to their viewers. The analysis showed that gender performativity expressed by the characters intend to normative sexual order, which punishes functions and expressions assigned to each gender. Positioning on the borders of what was attributed historically and culturally as male and female, bet on the fact that the presence of such characters opposite in such blockbusters flex notions of difference at the very moment in which, in addition to allegedly carried over from one genre to another, lie more in hybrid territories.
\end{abstract}

keywords: Queer studies. Gender. Cartoon characters.

\footnotetext{
${ }^{1}$ Doutorando em Ensino de Ciências e Educação Matemática na Universidade Estadual de Londrina. E-mail: afinocencio88@ gmail.com.

${ }^{2}$ Doutor em Educação Básica pela Universidade do Vale do Rio dos Sinos. Atualmente professor Associado do Departamento de Química da Universidade Estadual de Londrina.
} 


\section{Introdução}

A perspectiva que rege o estudo que ora se apresenta é inspirada pelas correntes de pensamento pós-estruturalistas $^{3}$ e pós-modernas. A profusão de sua proposta nasce sob a riqueza de alguns incômodos diante de hábitos corriqueiros, no caso aqui expresso, ocupar-se da posição de pessoas telespectadoras ${ }^{4}$. $\mathrm{Na}$ ordem do labor investigativo, vislumbra-se nas trincheiras da pesquisa acadêmica um crescente número de trabalhos ${ }^{5}$ que se dedicam à problematização de temas que são apresentados, diariamente e de forma massiva, aos que preenchem, temporariamente, o lócus de telespectadores.

Centraliza-se como foco desta proposta a seleção de efeitos de sentido veiculados por personagens de desenhos animados. Nesta escolha, encontrase expandida a noção de educação, pelo menos daquela entendida em sua modalidade formal e utilizada de forma majoritária. Concorda-se que a grande produção dos desenhos animados, como outros programas de televisão e demais veículos midiáticos - operam no sentido de que:

"Sem ter o objetivo explícito de ensinar, entretanto, é óbvio que elas ensinam alguma coisa, que transmitem uma variedade de formas de conhecimento que embora não sejam reconhecidas como tais são vitais na formação da identidade e da subjetividade" (SILVA, 2013, p. 140).

Um dos pontos que se convergem nos estudos pós-estruturalistas é a ênfase dada ao papel da linguagem. Distancia-se do legado deixado pela episteme moderna, que regia o modo de sere estar das pessoas em termos de estruturas e metanarrativas, fixas e condicionantes e ao embasar-se por este eixo que toma a educação como a noção descrita acima, entende-se que as imagens, discursos, cenas, episódios e todo o arsenal televisivo, toda sua trama lingüística e simbólica que compõem as grandes produções da teledramaturgia detém um potencial de subjetivação.

A crítica pós-estruturalista desloca a linguagem para nos oferecer significados e representações escorregadias as quais não dispõem uma realidade única, que entende uma via "correta" para a relação entre as coisas. Nos termos que orientaram este estudo:

[...] o pós-estruturalismo questiona as filosofias do sujeito que não levam em conta as condições externas de suas próprias possibilidades. Para o pós-estruturalismo, a ênfase na autoconsciência absoluta e no seu suposto universalismo é parte integrante dos processos que tendem a excluir o Outro, ou seja, aqueles grupos sociais e culturais que agem de acordo com critérios culturais diferentes. Em vez da autoconsciência, o pósestruturalismo enfatiza a constituição discursiva do eu - sua corporeidade, sua temporalidade e sua finitude, suas energias inconscientes e libidinais - e a localização histórica e cultural do sujeito (PETERS, 2000, p. 36).

Nessa perspectiva não há uma representação ideal pela qual se busca decifrar uma face legível, mas sim, como adverte Bujes (2005, p. 185), os objetos do mundo social "[...] são construídos discursivamente, para isso lançamos mão da linguagem falada ou escrita, mas utilizamos também sistemas de representação que nos permitem usar signos e símbolos para representar o que existe à nossa volta". Tais autores visibilizam o caráter sempre contingente e local que tangencia

${ }^{3}$ Guacira Lopes Louro (2001, p. 545) informa que a emergência do movimento queer ultrapassou as questões pontuais provenientes das políticas gays e lésbicas e estão compreendidas num quadro mais amplo do pós-estruturalismo.

${ }^{4}$ Sobre a escrita amparada pela gramática normativa, não faremos uso dos marcadores de gênero como os/as e @, uma vez que mantém o padrão binário acerca dos gêneros e trataremos aqui dos estudos queer, os quais extravasa esta padronização em limites binários. Também optamos propositalmente pelo não uso do x no lugar de o/a, haja vista inúmeras outras problemáticas geradas por este uso, como sua impossibilidade de pronúncia, a dificuldade para deficientes visuais leitores de tela que utilizam programas de computador para efetuar a leitura, sua não capacidade de se transformar em linguagem, ou seja, ficará sempre restrito ao texto, dentre outras. Optou-se, neste estudo, por um uso de 'pessoas' ou 'indivíduos' no lugar de palavras que assumissem a inflexão de gênero.

${ }^{5}$ A exemplo citamos aqui o texto "Memória e pedagogia no maravilhoso mundo da Disney", de Henri Giroux (2012). 
os processos de formação de subjetividades, deslocando seu interesse a gama de elementos que perfazem os corpos e os tornam possíveis, ao mesmo tempo em que lançam um olhar distanciado aos universalismos.

Levando em conta tais questões, admite-se, nesse estudo, um caráter performativo da linguagem (LOURO, 2001), que passa a assumir características como o decalque, o deslocamento, a reiteração e subversão dos signos, significantes e significados. De acordo com tais direcionamentos, pode-se presumir que os significados não são construções postas para sempre, estagnadas, mas que assumem caráter contingente, transitório, fazendo sentido somente nas tramas que integram uma relação discursiva entre elementos da linguagem. Convém destacar que o termo discursivo, presente neste artigo, é no sentido foucaultiano, para quem só faz sentido o entendimento do enunciado "[...] na estreiteza e singularidade de sua aceitação; [...] de fixar seus limites da forma mais justa, de estabelecer suas correlações com os outros enunciados a que pode estar ligado, de mostrar que outras formas de enunciação exclui" (FOUCAULT, 2013, p. 34).

É na capacidade de subversão dos significados pela linguagem, que existe potencialidade para que sejam subvertidas as próprias formas de submissão e lógicas de dominação. Em outros dizeres,

[...] os significados não correspondem a uma qualidade essencial do objeto que temos que desvelar; a essência das coisas nada mais é do que uma invenção humana, instituída nas trocas e negociações de sentido que estabelecemos intersubjetivamente. Deste modo, a linguagem não faz a mediação entre o que vemos e o pensamento, ela constitui o próprio pensamento (BUJES, 2005, p. 186).

As implicações provocadas por essa perspectiva são particularmente importantes quando se inclina a analisar que elementos transladam os programas e séries televisivas. Se estes podem ser pensados como elementos que não representam, mas constituem formas de ser no mundo, a ampliação das compreensões possibilitadas por este referencial assume particular importância para as questões de gênero.

Adota-se como suspeita que as instâncias midiáticas caracterizaram-se por disseminar traços homogêneos e normativos de formas de ser e estar no mundo - boa parte dos programas dos canais de comunicação obedece a um regime normativo que estabelece referência ao projeto de modernidade - a do ser humano universal, racional e dotado de consciência, subjacente a um regime, e não deslocam ou representam outras condutas ou modos de subjetivações ou subjetividades. Reforça-se, nesse sentido, a escolha de uma leitura inspirada nos referenciais pós-estruturalistas, uma vez que este "partilha uma ênfase comum no inconsciente e nas estruturas ou forças sociohistóricas subjacentes que constrangem e governam nosso comportamento" (PETERS, 2000, p. 37).

Com base, também, nas contribuições teóricas dos estudos queer - do inglês, estranho ${ }^{6}$, aquilo que de acordocomMiskolci(2015,p.21)“[...] emtermostanto políticos quanto teóricos, surgiu como um impulso crítico em relação à ordem sexual contemporânea" - propõem-se, aqui, visibilizar algumas personagens de desenhos animados cujos traços "escapam" do padrão binário de gênero inerentes a esse projeto de modernidade referido anteriormente; admite-se que tais papéis representam-se como fugazes às sanções normatizantes/normalizadoras hegemônicas que, por isso mesmo, são difíceis de serem circunscritas em uma das funções de gênero - masculino e feminino atribuída pelo regime gendrado normativo.

Reconhece-se como um ato político o simples fato de estas personagens desviantes figurarem no enredo dos desenhos selecionados, de forma que não foi preocupação desse estudo esta questão ter sido ou não entretecida de forma proposicional

\footnotetext{
${ }^{6}$ Mantém-se, neste caso, este adjetivo no masculino, pois pode estar voltado à atribuição de uma característica também para coisas, por exemplo, 'Isto tem formato estranho'
} 
pelos produtores das mídias selecionadas. Nosso particular interesse reside nos potenciais efeitos que estas podem proporcionar a quem está assistindo, à luz do referencial teórico adotado neste estudo.

Para atender ao que fora oferecido, apresentase, em um primeiro momento, o uso que se fez da terminologia pedagogia queer, bem como se buscou precisar um modo pelo qual este se fez funcionar nesse estudo. Em um momento posterior, trazem-se as personagens propriamente ditas a um possível regime analítico proporcionado por tais teorizações, das quais se entende aqui que, antes de convergirem no sentido de visibilizar novas identidades, constroem outras perspectivas de sexualidade que aludem àquelas que sempre existiram, mas que, por um conjunto de fatores, foram restringidas "às margens".

\section{Pedagogias Queer: Direcionando os Holofotes à Diferença}

Primeiramente é preciso justificar a adjetivação feita ao substantivo pedagogia. Da mesma forma com que esta vem sendo feita ao processo educativo em outras modalidades - educação indígena, educação para a diversidade sexual, educação do campo - ao processo pedagógico tem sido atribuída uma série de novas adjetivações, salientando campos emergentes para os quais este processo se direciona. A adjetivação aqui levada em conta é resultado, primeiro, de uma questão política, mais precisamente, consequência dos novos movimentos sociais que eclodiram na década de 1960, em que o movimento pelos direitos civis da população negra, o movimento feminista da segunda onda e o movimento homossexual organizam-se atribuindo caráter de problema a questões até então não centralizadas. O que tais movimentos ansiavam como demandas em comum era justamente que os processos de desigualdade iam além da questão de distribuição em diferentes classes econômicas.

"Alguns, mais ousados e de forma vanguardista, também começaram a apontar que o corpo, o desejo e a sexualidade, tópicos antes ignorados, eram alvo e veículo pelo qual se expressavam relações de poder" (MISKOLCI, 2015, p. 22). De forma ainda mais específica, Louro (2001) assinala que a ação política empreendida por militantes desses movimentos torna-se mais visível, assumindo um caráter libertador que, por sua vez, criticou a heterossexualização das sociedades.

Com as contribuições do movimento feminista, homossexual e, também, com as teorizações do filósofo francês Michel Foucault ${ }^{7}$ sobre a análise dos mecanismos disciplinares ${ }^{8}$, pôde-se pensar a questão da sexualidade como ironia de um dispositivo, o dispositivo de sexualidade. A ação desse e de qualquer outro dispositivo se dá de forma sutil, na maioria das vezes imperceptível, exercendo-se amplamente por meio de "intervenções capilares" de um conjunto heterogêneo "[...] que engloba discursos, instituições, organizações arquitetônicas, decisões regulamentares, leis, medidas administrativas, enunciados científicos, proposições filosóficas, morais, filantrópicas" (FOUCAULT, 2003, p. 244).

A necessidade de pôr em prática tal dispositivo teve origem no contexto da ascensão da burguesia, da explosão demográfica e desenvolvimento industrial que marcaram o século XVI. Em uma leitura foucaultiana (FOUCAULT, 2003, 2014), a circulação desse dispositivo passa a ser posta em prática no reconhecimento de que a mecânica geral do poder que vigorou nas sociedades do tipo feudal, em que o soberano regia o poder e o exercia sobre seu súdito, passa a ser insatisfatória frente a novas

\footnotetext{
${ }^{7}$ Guacira Louro (2001, p. 547) chega a declarar que os insights do filósofo sobre o campo da sexualidade foram diretamente relevantes para a formulação da teoria queer.

8 De acordo com Stuart Hall (1999) os mecanismos disciplinares descritos por Michel Foucault estão entre os cinco grandes avanços que marcaram a teoria social e as Ciências Humanas na segunda metade do século XX. As outras quatro são: as tradições que caracterizaram o pensamento marxista; a afirmação da existência de um inconsciente na estrutura da psique humana por Freud; a virada lingüística iniciada por Saussure e o impacto do movimento feminista.
} 
condições que se descortinavam naquele momento. O exercício de poder que se dava até aqui era eminentemente repressivo, atendendo aos interesses superiores exclusivos das pessoas que exerciam o papel de soberanas, e funcionava até o momento em que se detinha certo controle na quantidade de indivíduos sobre os quais este era exercido. Com o progressivo aumento da população a qual seria cada vez mais difícil de controlar (além de um processo cada vez mais custoso) somado a um explosivo processo de industrialização, passou-se a admitir tal modelo como inoperante, ansiando pela urgência de outra configuração.

Em sua obra 'A vontade de Saber', primeiro volume de História da sexualidade, Foucault (2014) buscou formular que os Estados nacionais passam a se preocupar com a produtividade e, para isso, acionam uma série de medidas, dentre elas as voltadas para o controle de natalidade, ao olhar atento às práticas sexuais dos grupos distintos. Em suas palavras:

Um rápido crepúsculo se teria seguido à luz meridiana, até as noites monótonas da burguesia vitoriana. A sexualidade é, então, cuidadosamente encerrada. Muda-se para dentro de casa. A família conjugal a confisca. E absorve-a inteiramente, na seriedade da função de reproduzir. Em torno do sexo, se cala. O casal, legítimo e procriador, dita a lei. Impõese como modelo, faz reinar a norma, detém a verdade, guarda o direito de falar, reservando-se o princípio do segredo. No espaço social, como no coração de cada moradia, um único lugar de sexualidade reconhecida, mas utilitário e fecundo: o quarto dos pais (FOUCAULT, 2014, p. 7-8).

Essa nova e diferenciada mecânica do poder, voltada à produtividade que caracterizou a transição do século XVI para o século XVII, passa, doravante, a se exercer de forma difusa entremeando o tecido social. É esta formatação do poder que Foucault caracterizou em suas obras como mecânica do poder disciplinar, que passa a garantir formas de sujeição constantes cujo objetivo é sempre o de impor um comportamento dócil.
Disso decorre que o poder passou a ser exercido "[...] em dois pólos de desenvolvimento, interligados por todo um feixe complexo de relações" (FOUCAULT, 2014, p. 131): um primeiro, centrando-se no corpo dos indivíduos, adestrando-os, assujeitando-os com interesse em sua capacidade produtiva, caracterizando uma unidade "anátomo-política do corpo humano"; e um segundo, centrado na população, regulando regimes disciplinares ligados à vida, caracterizando uma unidade "bio-política da população". É a este poder que toma a população como objeto de ordem que Foucault (2014) consagrou pelo termo biopoder e é este quem mantém íntima relação com a noção de dispositivo, no caso o de sexualidade.

Mas qual o intuito dessa apresentação dos novos mecanismos disciplinares e a introdução da noção de dispositivo neste trabalho? O que isso tem a ver exatamente com a pedagogia queer? Nesse momento, é imprescindível estabelecer esses entrelaçamentos.

O primeiro deles é a admissão de que este dispositivo de sexualidade, que funcionou como instrumento fundamental para o estabelecimento do capitalismo industrial e das sociedades burguesas, ainda vigora e tenta manter eficácia em nossas sociedades contemporâneas. Este poder disciplinar está disseminado nos capítulos das novelas, nas propagandas, nas páginas das revistas de entretenimento, nos programas de rádio, nos livros didáticos, nos folders e outdoors de divulgação comerciais, e como residiu o interesse até aqui, nos desenhos animados, dispondo, majoritariamente, de uma centralidade de protagonismo exercido por casais heterossexuais, bem como a expressões de gênero demarcadas, estabelecidas socialmente às pessoas. Nessa função, o advento da pedagogia também ocupa papel essencial: detém-se ao controle do corpo infantil, oferecendo às crianças por diversos meios e desde a tenra infância essa centralidade ocupada pelo casal heterossexual e por essas expressões demarcadas de gênero. Esse regime discursivo operado pela pedagogia nesse 
momento pode ser lido como aquele que mantém o Estado "em funcionamento".

Reconhece-se que essa flexibilização da noção de poder se dá na forma de uma rede móvel e fluida, a qual acaba por garantir, na centralidade de suas próprias conformações, seu exercício em direções contrárias: as resistências, estas distribuídas de modo irregular "[...] introduzem na sociedade clivagens que se deslocam, rompem unidades e suscitam reagrupamentos, percorrem os próprios indivíduos, recortando-os e os remodelando, traçando neles, em seus corpos e almas, regiões irredutíveis" (FOUCAULT, 2014, p. 105). Dessa forma, o exercício de poder não apenas heteronormativo, mas que também impõe sanções gendradas que propõem comportamentos e modos de ser nos desenhos infantis, passam a reconhecer, no avançar das últimas décadas, o advento de personagens que podem ser lidas enquanto nós desta mesma rede que não é hermética nem massiva, mas expansiva, flexível - e que escapam das sanções impostas por este dispositivo retratado até aqui. Louro (2009, p. 90) discorre a respeito desse processo de heteronormatividade como elemento que reitera, de forma compulsória, a norma heterossexual; segundo esta lógica, supõe-se "[...] que todas as pessoas sejam (ou devam ser) heterossexuais - daí que os sistemas de saúde ou de educação, o jurídico ou o midiático sejam construídos à imagem e semelhança desses sujeitos".

A segunda consideração é a de que a noção de queer passa a surgir "[...] nesse espírito iconoclasta de alguns membros dos movimentos sociais expresso na luta por desvincular a sexualidade da reprodução, ressaltando a importância do prazer e a ampliação das possibilidades relacionais" (MISKOLCI, 2015, p. 22). Foucault (2014, p. 8) considera que esta lógica que assinalou a dinâmica hipócrita de nossas sociedades - mantendo o que chamou de "sexualidades ilegítimas" como periféricas, aquelas que deveriam "[...] incomodar noutro lugar [...] não nos circuitos da produção" manteve essas sexualidades restritas, insularizadas a locais específicos de aparição e expressão, como os prostíbulos. São essas sexualidades as quais não orbitam em torno de uma lógica reprodutiva que nos interessam aqui.

Trata-se de reconhecer novas expressões individuais e coletivas, que passaram a ser contempladas nas produções televisivas. Concordando com Louro (2001, p. 542) de que esse embate mereceria atenção especial de estudiosos culturais e educadores, busca-se encerrar esta seção com sua síntese de que:

\begin{abstract}
O grande desafio não é apenas assumir que as posições de gênero e sexuais se multiplicaram e, então, que é impossível lidar com elas apoiadas em esquemas binários; mas também admitir que as fronteiras vêm sendo constantemente atravessadas e - o que é ainda mais complicado - que o lugar social no qual alguns sujeitos vivem é exatamente a fronteira.
\end{abstract}

É nesse ínterim que se estabelece o entendimento de que tal compreensão, associada ao âmbito pedagógico, assume um papel imprescindível na visibilidade de parte da população que "escapa" (resiste) ao poder desse dispositivo. Neste ponto, retoma-se Miskolci (2015, p. 24) que lembra que a problemática queer é justamente a da abjeção. O termo, "abjeção", “[...] se refere ao espaço a que a coletividade costuma relegar aqueles e aquelas que considera uma ameaça ao seu bom funcionamento, à ordem social e política”. Essa parte que comumente é renegada, motivo de desprezo e nojo, muitas vezes aparecendo de maneira parodiada e satirizada é justamente a que será trazida na próxima seção.

\section{Uma Leitura Queer das Telinhas: Personagens Fronteiriços}

Apresenta-se nesta última seção, a exemplo do que se estabeleceu como potencial leitura ancorada nos estudos queer, três exemplos de personagens de desenhos de emissoras distintas a fim de ilustrar a problematização teórica que se buscou estabelecer até aqui. 
A primeira ficção interessante para esta discussão é a da personagem "Ele”, que integra o quadro daquelas que ocupam a posição de pessoas vilãs no cartoon "As meninas Superpoderosas". Apesar de flexionado no masculino, a aparição desta personagem e toda sua construção denotam uma série de estridências que incidem diretamente na noção hegemônica do que é ser masculino veiculado na forma padronizada/ normatizada. "Ele" usa botas de cano alto, ao mesmo tempo em que barba aparada ao estilo cavanhaque, usa blush e rímel, seu uniforme é composto por um colan vermelho adornado com pompons cor-de-rosa, e sua voz alterna entre o grave e o agudo de acordo com seu aparente estado de espírito (Figura 1- a).

Figura 1 - Personagens passíveis de uma leitura queer

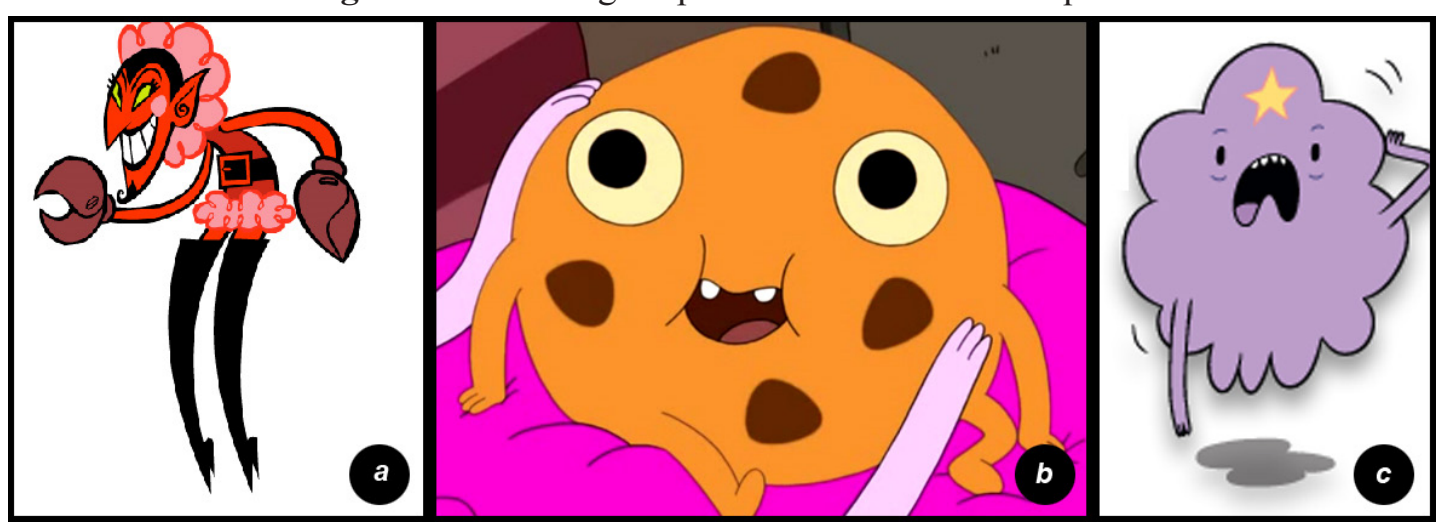

a) Ele; $\quad$ b) Biscoito;

c) Princesa Caroço.

Fonte: Power Puff Wiki (2016) e Adventure Time (2016b, 2016c).

É interessante notar que no decorrer dos episódios há certo embate com relação à questão de gênero das personagens que protagonizam e as de "Ele": diferentemente das demais personagens vilãs que encenam as problemáticas da fictícia cidade de Townsville, "Ele" é o único cujas intenções primeiras não se inclinam na destruição da cidade em si (diferente de outros vilões, como o "Macaco Louco"), mas sim das próprias meninas, ora deslocando a competitividade entre meninosmeninas, que poderia ser entendida em termos de misoginia, ora, junto à sua construção imagética, apropriando-se performativamente de roupas, timbre agudo, comportamentos que socialmente foram relegados/associados às mulheres. Em um dos episódios característicos da série, "Ele" ressuscita os "Meninos Desordeiros" e dá a eles uma vacina para que fiquem imunes aos beijos das meninas. $\mathrm{O}$ conjunto de características expressas pelas meninas superpoderosas parece incomodá-lo no decorrer dos episódios. Sua construção imagética e performativa, de qualquer forma, não está adequada a uma materialização imposta, garantindo um efeito subversivo à sua personagem.

"Ele" é passível de serpensado como uma alusão à imagem bíblica do diabo, remetendo à

\footnotetext{
${ }^{9}$ Clássico do canal Cartoon Network Studios, As meninas Superpoderosas (The Powerpuff Girls) como ficou conhecido no Brasil, foi criado e escrito por Craig McCracken e se trata da história de três meninas: Florzinha, Lindinha e Docinho, criadas em laboratório pelo professor Utônio, que acidentalmente deixou cair o "elemento X" no que seria a fórmula da "menina perfeita", dando a elas superpoderes. A série teve ampla divulgação e procura nos Estados Unidos no final da década de 1990 e início dos anos 2000 e, no Brasil, foi exibida regularmente até 2005 pelo Programa "Bom Dia \& Cia", mas posteriormente saiu do ar, sendo exibidas apenas algumas reprises no mesmo canal. Fonte: Wikipedia.
} 
margem de Townsville; é uma figura estranha em sua condição de nem homem, nem mulher, mas híbrida, performática, abjeta; é um elemento queer no desenho com o qual os espectadores podem se identificar, mas, também, tencionar outras possibilidades de ser que não estão restritas ao regime normativo das sexualidades binárias.

Outras duas personagens que acentuam a leitura queer são "Princesa Biscoito" e "Princesa Caroço" (Figura 1 - b; Figura 1- c, respectivamente); ambas integram o cartoon "Hora de aventura ${ }^{10 "}$. De maneira diferente do que se pode chamar de personalidade boa ou má em "As meninas superpoderosas", essa distinção não é estabelecida de forma tão cristalina em "Hora de Aventura".

A problemática que gira em torno de "Biscoito" parece tratar de uma exigência da personagem em ser tratada como uma princesa pelos demais integrantes da terra de Ooo. Sua intenção, em um dos episódios, é a de roubar a coroa da "Princesa Jujuba", para que seja chamada e tratada como princesa oficial do reino. Para isso, chega, inclusive, a manter como refém algumas personagens secundárias do cartoon. Ainda que ser tratada como uma princesa ocupe, no quadro estabelecido nesta produção, um papel de poder, a personagem não manifesta qualquer problema ao assumir o título no feminino, dando muitas margens de interpretação para que se pense seu papel de gênero, que não parece ser preocupação central desta personagem.

Dotada de outras peculiaridades, a "Princesa Caroço" é uma personagem que flutua como nuvem, fala palavrões, embora no cartoon eles apareçam substituídos pelo termo "caroço"; tem namorados ao longo da série, é metida, rude e mal educada. Diferente de "Biscoito", a "Caroço" é uma princesa, a princesa do "reino dos caroços".
Cada uma à sua maneira decalca o emprego da terminologia princesa, comumente associada a uma personalidade feminina, elementos meigos, suaves e delicados. É notório que ambas têm dubladores em vez de dubladoras, e não são personagens humanas, o que já borra as tentativas de classificação dessas personagens em homem ou mulher. Ao se estabelecer uma breve alusão às princesas da Disney das primeiras produções, como "Branca de Neve" e "Bela Adormecida", por exemplo, acirram-se ainda mais as construções discursivas de princesa comparando estas personagens às integrantes de "Hora de Aventura".

Estipula-se, dessa forma, a leitura de que essas personagens são passíveis de provocar interpretações que rompem com os modelos lineares de conduta daquilo que se espera socialmente para a relação sexo-gênero-sexualidade, pervertendo, nesse sentido, a noção de ordem. Embora, na maioria das vezes os enfrentamentos queer se fazem de maneira transgressiva e perturbadora (LOURO, 2001), no lócus de desenhos animados expressamse na reificação das personagens de maneira mais branda. É justamente por expressarem essas formas de leitura de maneiras mais sutis que se credita a essas produções mecanismos eficientes de ruptura.

Reiterando Louro (2001, p. 546) “[...] queer significa colocar-se contra a normalização - venha ela de onde vier. Seu alvo mais imediato de oposição é, certamente, a heteronormatividade compulsória da sociedade". O pós-estruturalismo, novamente, questiona os supostos status privilegiados das distinções ou dicotomias que por ventura se tente atribuir a essas personagens, "elas não são nem fundacionais nem exclusivas da forma que os estruturalistas supõem que elas sejam" (PETERS, 2000, p. 40). Daí chamar a atenção para os perigos das categorizações nas tentativas estabelecidas

\footnotetext{
${ }^{10}$ Adventure Time ou Hora de Aventura, como levou seu título no Brasil, é uma série de desenho animado americana desenvolvido por Pendleton Ward para o Cartoon Network. A série segue as aventuras de Finn, um garoto humano aventureiro, e o seu melhor amigo Jake, um cão com poderes mutantes que lhe permitem alterar sua forma e tamanho consoante à sua vontade. Finn e Jake habitam a pós-apocalíptica terra de Ooo, onde interagem com outras personagens da série, como a Princesa Jujuba, o Rei Gelado, e Marceline, a Rainha dos vampiros. (ADVENTURE TIME, 2016c).
} 
pelos estruturalistas. Essas personagens advertem de alguma forma, sobre as limitações de uma leitura que busque padronizá-las em um regime que leva em conta o binômio masculino-feminino sobre o qual não respondem.

Demarcando o regime da diferença destas personagens, Peters (2000, p. 41) contribui, ainda, da seguinte forma:

Em sua crítica, os pós-estruturalistas argumentam que as democracias liberais modernas constroem a identidade política com base em uma série de oposições binárias (por exemplo, nós/eles, cidadão/não-cidadão, responsável/irresponsável, legítimo/ilegítimo) que têm o efeito de excluir certos grupos culturais ou sociais [...] os países ocidentais concedem certos direitos aos seus cidadãos (os direitos se tornam dependentes da cidadania), passando a considerar os não-cidadãos (isto é, os imigrantes, aqueles que buscam asilos políticos e os refugiados) como "estranhos".

Nessa leitura podem-se pensar essas personagens representando o Outro, aquele elemento que se opõe à norma; elementos passíveis de "filosofias da diferença", que criticam de forma direta "os valores supostamente universais da cultura política (eurocêntrica) do Iluminismo, questionando, em particular o estabelecimento de certos direitos" (PETERS, 2000, p. 42). Percebe-se, assim, que todo regime binário de classificação está além da neutralidade, consagrando em seus pares de opostos, relações de poder em que um dos termos sempre está "acima" do outro. No caso dessas personagens cujas narrativas constroem sexualidades que não se esgotam ao papel reprodutivo, ampliando, assim, as formas de expressão sexuais, podem ser lidas como o par que se opõe aos valores da cultura ocidental de que fala Foucault, referindo-se ao casal monogâmico, à norma reprodutiva e bem feitora, mas também podem, no momento em que ganharam essa visibilidade, representar uma crítica a este mesmo modelo.

Nessa altura, pode-se indagar: "Por quais motivos essas personagens não eram representadas (ou até eram, mas sempre de forma irrisória) nas produções midiáticas, sobretudo em desenhos animados?". E as possíveis respostas que emergem como balbuciares a esse questionamento provêm, na escolha eleita nesta proposta, nas noções empreendidas por Foucault. Os excertos desse autor trazidos neste texto advêm da noção de governamentalidade, empreendida por ele em seus últimos trabalhos. Tal conceito se entretece juntamente aos meios pelos quais a arte de governar estatal se utiliza, a partir do século XVI, para reger os corpos no interior de um regime da política liberal moderna. Esta arte de governar aparece difusa e se dá de forma capilar na sociedade, buscando "capturar" as condutas pessoais pelo governo de si, o governo das almas pelas doutrinas pastorais e o governo das formas jovens, destacando o papel político da pedagogia.

Quando se torna possível adjetivar o termo pedagogia na forma de pedagogia queer, estamos assinalando o advento de uma nova ordem política em que esses regimes descritos por Foucault já se encontram "afrouxados", seja pelo reconhecimento de que tal ordem é um processo constante de reiteração e manutenção artificial, seja pelo próprio papel desempenhado pelas resistências:

Da mesma forma que a rede das relações de poder acabam formando um tecido espesso que atravessa os aparelhos e as instituições, sem se localizar exatamente neles, também a pulverização dos pontos de resistência atravessa as estratificações sociais $\mathrm{e}$ as unidades individuais. E é certamente a codificação estratégica desses pontos de resistência que torna possível uma revolução (FOUCAULT, 2014, p. 105).

A resistência que oferece o aparecimento e papel desempenhado por essas personagens, no sentido de que assumem posições de gênero e papéis sexuais que "deram as costas" aos regimes binários, é ao mesmo tempo exercida por este aparecimento, cumprindo um propósito, um propósito queer de, nas palavras de Tomaz 
Tadeu da Silva (2013, p. 107) “[...] nos obrigar a considerar o impensável, o que é proibido pensar, em vez de simplesmente considerar o pensável, o que é permitido pensar".

\section{Considerações Finais}

Amparando-se nos referenciais pósestruturalistas, admitiu-se que o papel da linguagem que se refere às personagens e à sua sexualidade não se resume ao plano das constatações e descrições das mesmas, não aludem a algo que querem imitar da sociedade, mas, no instante mesmo de sua execução, constrói aquilo que nomeia.

No regime do dispositivo de sexualidade apresentado e sua veiculação por inúmeras instâncias midiáticas, como os desenhos animados, a leitura foucaultiana somada à perspectiva dos estudos queer permitiram aqui, dentre outras coisas, a compreensão de que ao mesmo tempo em que a heteronormativa é reiterada a todo o momento com a finalidade de manutenção de papéis reprodutivos e dóceis, circunscritos a uma governamentalidade própria, permitem, pela simples tentativa inerente de manutenção desse sistema, a produção de corpos que escapam a essas normativas. Nesse sentido, as personagens trazidas detêm um papel imprescindível e socialmente indispensável para constituírem a visibilização de regimes de sexualidades que permeiam as fronteiras.

Pervertendo os ranços de uma episteme que ainda se mantém na ordem dos dias e das trocas, reconhece-se que essas personagens exploram os limites do impensável, mas não esgotam as possibilidades de que sejam pensadas uma variedade de inúmeras outras personagens e temas.

\section{Referências}

ADVENTURE TIME. In: Wikipédia. Disponível em: <https://pt.wikipedia.org/wiki/Adventure_ Time>. Acesso em: 13 abr. 2016a.
- Princesa biscoitosa. Disponível em:

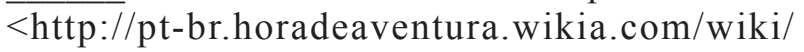
Arquivo:Princesa_biscoitosa.png $>$. Acesso em: 13 abr. 2016 b.

. Princesa caroço. Disponível em: $<$ http:// pt-br.horadeaventurafanfictionn.wikia.com/wiki/ Princesa_Caro\%C3\%A7o $>$. Acesso em: 13 abr. $2016 c$.

BUJES, M. I. E. Infância e poder: breves sugestões para uma agenda de pesquisa. In: BUJES, M. I. E.; COSTA, M. V. (Org.). Caminhos investigativos III: riscos e possibilidades de pesquisar nas fronteiras. Rio de Janeiro: DP\&A, 2005. p. 179-197.

FOUCAULT, M. A arqueologia do saber. 8. ed. Rio de Janeiro: Forense Universitária, 2013.

. História da sexualidade 1: a vontade de saber. São Paulo: Paz e Terra, 2014.

. Sobre a história da sexualidade. In: FOUCAULT, M. Microfísica do poder. 18. ed. Rio de Janeiro: Graal, 2003. p. 363-406.

GIROUX, H. A. Memória e pedagogia no maravilhoso mundo da Disney. In: SILVA, T. T. (Org.). Alienígenas na sala de aula. 10. ed. Petrópolis: Vozes, 2012. p. 83-100.

HALL, S. A identidade cultural na pósmodernidade. Tradução de Tomaz Tadeu da Silva e Guacira Lopez Louro. 3. ed. Rio de Janeiro: DP\&A, 1999.

LOURO, G. L. Heteronormatividade e homofobia. In. JUNQUEIRA, R. D. (Org.). Diversidade sexual na educação: problematizações sobre a homofobia na escola. Brasília: MEC/Unesco, 2009. p. 85-93.

. Teoria queer: uma política pós-identitária para a educação. Revista de Estudos Feministas, Florianópolis, v. 9, n. 2, 2001 . Disponível em: $<$ http://www.scielo.br/pdf/ref/v9n2/8639.pdf $>$. Acesso em: 20 out. 2015.

MISKOLCI, R. Teoria queer: um aprendizado pelas diferenças. 2. ed. Belo Horizonte: Autêntica, 2015. 
PETERS, M. Pós-estruturalismo e filosofia da diferença: uma introdução. Belo Horizonte: Autêntica, 2000.

POWER PUFF WIKI. Ele. Disponível em: $<\mathrm{http}: / / \mathrm{pt}-$ br.powerpuff.wikia.com/wiki/Ele>. Acesso em: 5 mar. 2016.

SILVA, T. T. Documentos de identidade: uma introdução às teorias do currículo. 3. ed. Belo Horizonte: Autêntica, 2013. 
